\title{
Prevalence of blood pressure among students in Jiangsu Province, China
}

\begin{abstract}
Taha Hussein Musa ${ }^{1,2, * \#}$, Wei Li ${ }^{1 \#}$, Tauseef Ahmad $^{1 \#}$, Chu Jinjin ${ }^{1 \#}$, Hassan Hussein Musa ${ }^{3}$, Pingmin Wei ${ }^{1, *}$
\#Contributed equally

${ }^{1}$ Key Laboratory of Environmental Medicine Engineering, Ministry of Education; Department of Epidemiology and Health Statistics, School of Public Health, Southeast University, Nanjing, 210009, Jiangsu Province, China

${ }^{2}$ Biomedical Research Institute, Darfur College, Nyala, Sudan

${ }^{3}$ Faculty of Medical Laboratory Sciences, University of Khartoum, Khartoum, Sudan

Correspondence

ABSTRACT

Aim: Obesity and Blood Pressure (BP) is a serious public health issue. The study aims to assess the prevalence of BP and the factors associated with High Blood Pressure (HBP) among student in Jiangsu Province, China. Methods: A cross-sectional epidemiological study. A total of 101886 students (62,065 boys and 39,821 girls) aged range from 7-22 years were recruited in 2010-2013. Anthropometric measurements and BP prevalence were measured, and in addition, body mass index (BMI) was calculated. We assess the prevalence of BP according to the National Blood Pressure Reference for Chinese Han children and adolescents. Results: A significant difference was observed in HBP prevalence in terms of student gender, region, age and $B M I(P<0,001)$. Overweight and obesity were significantly associated with HBP $(P<0.001)$. Conclusions: The findings convey an important message to the parents, health institutions that urgent action is needed to enhance effective control of HBP among the overweight and obese students, and among those are living in a rural area.
\end{abstract}

Taha Hussein Musa, Key Laboratory of Environmental Medicine Engineering, Ministry of Education; Department of Epidemiology and Health Statistics, School of Public Health, Southeast University, Nanjing, 210009, Jiangsu Province, China

Biomedical Research Institute, Darfur College, Nyala, Sudan

Email: taha.hm99@yahoo.com (THM)

\section{Correspondence}

Pingmin Wei, Key Laboratory of Environmental Medicine Engineering Ministry of Education; Department of Epidemiology and Health Statistics, School of Public Health, Southeast University, Nanjing, 210009, Jiangsu Province, China

Email: mpw1963@126.com (PW)

\section{History}

- Received: 2019-Jul-22

- Accepted: 2019-Aug-17

- Published: 2019-Aug-28

DOI :

https://doi.org/10.15419/bmrat.v6i8.560

\section{Check for updates}

\section{Copyright}

(C) Biomedpress. This is an openaccess article distributed under the terms of the Creative Commons Attribution 4.0 International license.

Key words: Blood Pressure (BP), Jiangsu Province, Student, Body Mass Index (BMI)

\section{INTRODUCTION}

Obesity is a global health problem ${ }^{1}$. The prevalence was significantly increased in all countries ${ }^{1-3}$. Approximately 2.8 million people were dying each year because of overweight ${ }^{4}$. Body Mass Index (BMI) was commonly used for screening overweight and obese in clinical practice and population survey ${ }^{5}$. High blood pressure (hypertension) was significantly increased among Chinese recently ${ }^{6}$. Obesity is a risk factor for diabetes, stroke, cardiovascular diseases and their complications ${ }^{6,7}$. Ten million persons in the world die annually with $\mathrm{BP}^{6}$. Childhood $\mathrm{BP}$ is a significant predictor of adulthood $\mathrm{BP}^{8}$.

The trend of BP prevalence was reported among Chinese children and adolescents ${ }^{3,6,9-14}$. However, little is known about their association with gender, age, region and BMI level among student in Jiangsu Province. The province, is located in eastern-central coastal of China, covered $102,600 \mathrm{~km}^{2}$ and total population 80,400,000 in 2018 (https://en.wikipedia.org/ wiki/Jiangsu). The aim was to assess the prevalence of HBP and NBP among students.

\section{METHODS}

A cross-sectional study was carried out during September 2010 to September 2013. The study subjects includes male and female students aged 7-22 years enrolled in Students Physical Fitness and Health
Table 1: Association between Blood Pressure and study variables

\begin{tabular}{lccc}
\hline Variables & S.E. & $\begin{array}{c}\text { P- } \\
\text { value }\end{array}$ & $\begin{array}{c}\text { OR } \\
(\mathbf{9 5 . 0 \%} \text { C.I. })\end{array}$ \\
\hline $\begin{array}{l}\text { Gender } \\
\text { (Male/Female) }\end{array}$ & 0.05 & 0.001 & $\begin{array}{c}0.77 \\
(0.69-0.85)\end{array}$ \\
$\begin{array}{l}\text { Region } \\
\text { (Urban/Rural) }\end{array}$ & 0.05 & 0.001 & $\begin{array}{c}1.19 \\
(1.09-1.31)\end{array}$ \\
Age in years (7-11) & & 0.001 & Reference \\
12-14 & 0.07 & 0.001 & $\begin{array}{c}2.21 \\
(1.91-2.56)\end{array}$ \\
15-17 & & & 2.42 \\
18-22 & 0.07 & 0.001 & $(2.09-2.80)$ \\
& & & 0.83 \\
BMI (Normal & 5.40 & 0.001 & $(0.77-0.90)$ \\
weight) & & & Reference \\
Overweight & 0.06 & 0.001 & 1.27 \\
& & & $(1.12-1.44)$ \\
Obesity & 0.06 & 0.001 & 2.44 \\
Constant & & & $(2.15-2.75)$ \\
\hline & 0.13 & 0.001 & 0.017 \\
\hline
\end{tabular}


A.

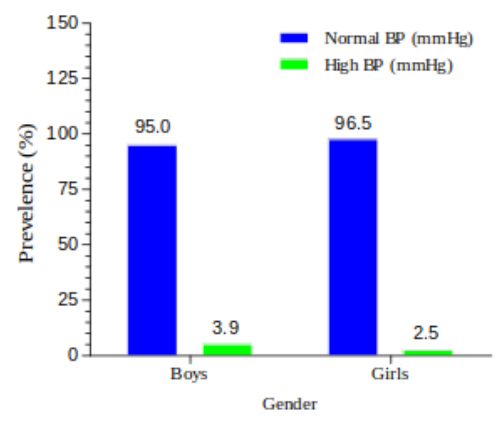

C.

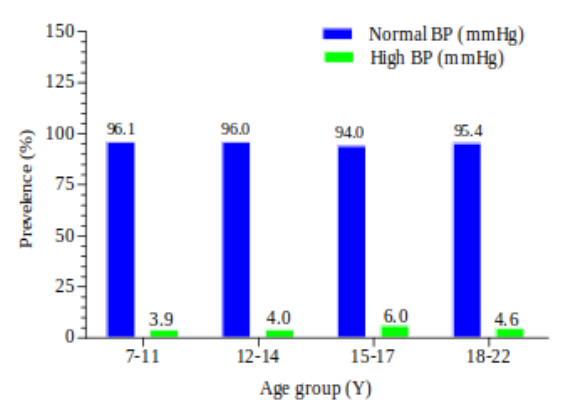

B.

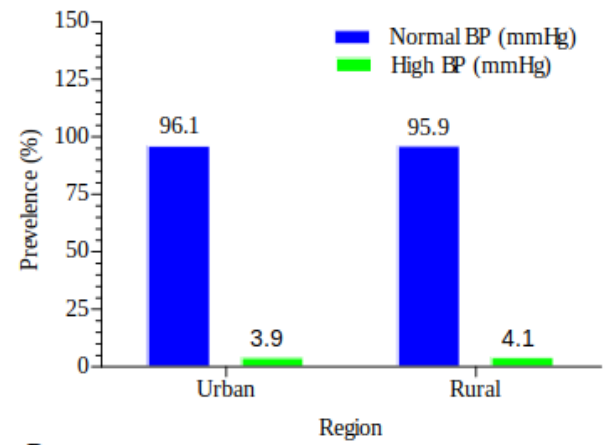

D.

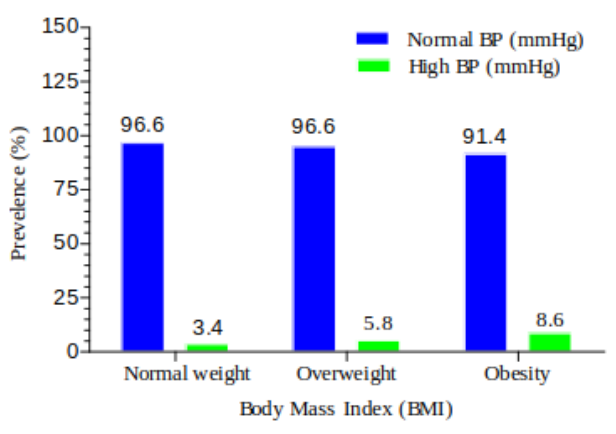

Figure 1: A): Blood pressure prevalence based gender; B): Region wise distribution, C): Age wise distribution, D): BMI wise distribution; Gender, region, age and BMI differences $P<0.001$

Surveys (SPFHS). The study population were randomly selected from 10 universities and 82 schools in Jiangsu Province, resulting in an estimated sample of, 101,886 students $(62,065$ boys and 39,821 girls). Data were collected by trained health staff and physician from Jiangsu Center for Disease Prevention and Control health team.

Students BP was assessed using a portable digital monitors Omron HEM 705 CP (OMRON, Kyoto, Japan), and blood pressure was measured on the right arm twice, in the morning and, no less than $30 \mathrm{~min}$ utes after breakfast, when children had empty bladders, after at least 5 minutes of rest, sitting with back support and feet on the ground, without moving or talking ${ }^{12}$.

Normal Blood Pressure (NBP) was defined as anyone with Systolic Blood Pressure 120 -129 (mmHg), and Diastolic Blood Pressure is $<80$ ( $\mathrm{mmHg}$ ). High Normal Blood Pressure for anyone with Systolic Blood Pressure 130-139 (mmHg) or Diastolic Blood Pressure is $80-89(\mathrm{mmHg})$. The average value of three $\mathrm{BP}$ readings was recorded. HBP and NBP prevalence were evaluated ${ }^{13}$, and update of the age and gender- specific BP cutoffs for Chinese children and adolescents reference $^{15}$. Student body Mass Index (BMI) was calculated from height and weight. BMI cutoff recommended by Working Group on Obesity in China $^{16}$. The study protocol was approved by the Institutional review board of School of Public Health Southeast University, Nanjing. A written informed consent was obtained from each participant's parent for those in primary school. A total of 101,886 students were agreed to complete anthropometric measurement. All analyses were performed using SPSS version 25.0 for Windows (IBM SPSS, Chicago, IL, USA).

\section{RESULTS AND DISCUSSION}

There was a significant difference in the prevalence of $\mathrm{BP}$ between gender, region, age groups and BMI categories, respectively $(\mathrm{P}<0.001)$. BMI level had a higher $\mathrm{BP}$ among overweight and obese groups (Figure 1). $\mathrm{BP}$ was significantly $(\mathrm{P}<0.001)$ associated with the rural area, age 12-14, age 15-17, and BMI level, including overweight, and obese group (Table 1)

The study confirmed that obesity could lead to serious health problems, ${ }^{2,7,8}$ there was a significant dif- 
ference in BP prevalence within the overweight and obese groups compared with the normal weight ${ }^{15}$ and the finding is line with previous studies ${ }^{2,3,7}$. Age, region and BMI level were significantly associated with the risk of HBP, similar to study reported in China ${ }^{6}$. In conclusions, the prevalence of BP was recorded high in females as compared to males. Results suggest that high BP is attributed mainly to a residential area (urban vs. rural), age groups and BMI level (Overweight and obese). Nevertheless, the risk of overweight and obesity are considered the significant risk factor associated with $\mathrm{BP}$ rate. In a public health point of view, early action is needed to reduce blood pressure and to control the factors related to high BP towards student health in the future.

\section{ABBREVIATIONS}

BP: Blood Pressure

BMI: Body Mass Index

HBP: High Blood Pressure

NBP: Normal Blood Pressure

SPFHS: Students Physical Fitness and Health Surveys

\section{AUTHORS' CONTRIBUTIONS}

Idea and study designed: THM

Acquisition of data: WL, TA, THM

Analysis and interpretation of data: LW, THM

Drafting of manuscript: TA, HHM

Study supervised: PW

\section{FUNDING}

The study was funded by Jiangsu Provincial Social Science Foundation, grant number 13TYA001.

\section{ACKNOWLEDGMENT}

The authors thank P.W and the staff of Jiangsu Health Literacy Promotion and Research Office for providing access to the student health data for analysis.

\section{REFERENCES}

1. Wang Y, Lobstein TI. Worldwide trends in childhood overweight and obesity. International Journal of Pediatric Obesity. 2006;1(1):11-25. Available from: 10.1080/17477160600586747.

2. Musa TH, Li WEI, LI XS, PU YP, Wei PM. Prevalence of Overweight and Obesity among Students Aged 7-22 Years in Jiangsu Province, China. Biomedical and Environmental Sciences. 2016;29(10):697-705. Available from: 10.3967/bes2016. 094.
3. Sun $H, M a Y, H a n D$, Pan CW, Xu Y. Prevalence and trends in obesity among Chinas children and adolescents. PloS One. 2014;9(8):1985-2010. Available from: 10.1371/journal.pone. 0105469.

4. Cole TJ, Bellizzi MC, Flegal KM, Dietz WH. Establishing a standard definition for child overweight and obesity worldwide: international survey. The BMJ. 2000;320(7244):1240-1240. Available from: 10.1136/bmj.320.7244.1240.

5. World Health Organization. 10 facts on obesity. Updated October 2017. http://www.who.int/features/factfiles/obesity/en /. (Accessed on 13.6.2019).

6. Dong B, Wang HJ, Wang Z, Liu JS, Ma J. Trends in blood pressure and body mass index among Chinese children and adolescents from 2005 to 2010. American Journal of Hypertension. 2013;26(8):997-1004. Available from: 10.1093/ajh/ hpt050.

7. Boyd GS, Koenigsberg J, Falkner B, Gidding S, Hassink S. Effect of obesity and high blood pressure on plasma lipid levels in children and adolescents. Pediatrics. 2005;116(2):442-6. Available from: 10.1542/peds.2004-1877.

8. Chen X, Wang Y. Tracking of blood pressure from childhood to adulthood: a systematic review and meta-regression analysis. Circulation. 2008;117(25):3171-3171. Available from: 10.1161/CIRCULATIONAHA.107.730366.

9. Ma J, Wang Z, Dong B, Song Y, Hu P, Zhang B. Quantifying the relationships of blood pressure with weight, height and body mass index in Chinese children and adolescents. Journal of Paediatrics and Child Health. 2012;48(5):413-421. Available from: 10.1111/j.1440-1754.2011.02221.x.

10. Dong B, Wang Z, Wang HJ, Ma J. Associations between adiposity indicators and elevated blood pressure among Chinese children and adolescents. Journal of Human Hypertension. 2015;29(4):236. Available from: 10.1038/jhh.2014.95.

11. Zhang YX, Zhao JS, Sun GZ, Lin M, Chu ZH. Prevalent trends in relatively high blood pressure among children and adolescents in Shandong. China Annals of Human Biology. 2012;39(3):259-63. Available from: 10.3109/03014460.2012. 681799.

12. Chen Z, Wang X, Wang Z, Zhang L, Hao G, Dong Y, et al. Assessing the validity of oscillometric device for blood pressure measurement in a large population-based epidemiologic study. Journal of the American Society of Hypertension. 2017;11(11):730-736. Available from: 10.1016/j.jash.2017.09. 004.

13. Dong Y, Ma J, Song Y, Dong B, Wang Z, Yang Z, et al. National Blood Pressure Reference for Chinese Han children and adolescents aged 7 to 17 years. Hypertension. 2017;70(5):897906. Available from: 10.1186/1471-2431-13-195.

14. Mi J, Wang TY, Meng LH, Zhu GJ, Han SM, Zhong Y, et al. Development of blood pressure reference standards for Chinese children and adolescents. Chinese Journal of Evidence Based Pediatrics. 2010;5(1):4-14.

15. Wang SR, Zhu YB, Cheng Y, Zhang YX. Profiles of blood pressure among children and adolescents with different body mass index categories in Shandong, China. Blood Pressure. 2018;27(1):56-61. Available from: 10.1080/08037051.2017. 1384308.

16. CY J. Cooperative Study on Childhood Obesity, Working Group on Obesity in China (WGOC). Report on Childhood Obesity in China (1): Body Mass Index Reference for Screening Overweight and Obesity in Chinese School-age Children. Biomedical and Environmental Sciences. 2005;18:390-400. Biomedical and Environmental Sciences. 